\title{
3D Photochemical Machining of Copper By using Colored Phototools
}

\author{
Bandu Kamble, Abhay Utpat, N.D. Misal, B.P Ronge
}

\begin{abstract}
Photochemical machining is an engineering production technique for the manufacturing of burr free and stress-free components in various industries. The thin, precision parts and complex geometries can be produced by using non-conventional machining process in diverse industries as aerospace, electronics automotive manufacturing. This paper focuses on study of three-dimensional photochemical machining at varying temperatures by using coloured photo tool. The process is starting with by designing of photo tool for different surface curvature. Cooper material was selected for experimentation, it has good electric and thermal conductivity. The control parameters selected were temperature, concentration and time. The temperature and time are varying parameter for etching. The depth of etch was measured by using Digital Micrometre having least count $0.001 \mathrm{~mm}$. The objective of this study is to achieve variable depth on two dimensional surfaces.3D PCM was carried out for flat surfaces followed by curved objects on copper.
\end{abstract}

Index Terms - Photo Chemical Machining, Photo tool, etching, Varying etching parameters.

\section{INTRODUCTION}

Photochemical machining (PCM) is one of the emerging non-conventional machining processes. PCM is also known as etching, photochemical machining, wet etching, photo etching, photochemical milling etc. The process is start with by creating required design called as photo tool in AutoCAD software and printed it on transparent sheet of plastic for etching. The photoresist is applied on metal surfaces. The design is kept on photoresist and exposed it by using high intensity ultraviolet light. The pattern is transferred on photoresist and It will be visible after development. The manufacturing process creates features by dissolving away the metal parts in etching process. There is no use of cutting tool for manufacturing of components, due to this the stresses and other defects normally arises from metal cutting is absent in the final part of PCM [1-6].

The major steps involved on 3D PCM is given below

$>$ Preparation of photo tool

$>$ Selection of base metal

$>$ Preparation of workpiece

$>$ Photoresist coating

Bandu Kamble, Research Scholar,SVERI's College of Engineering, Pandharpur

Abhay Utpat, Professor,Department of mechanical Engineering, SVERI's College of Engineering, Pandharpur

N.D. Misal, Professor,Department of mechanical Engineering, SVERI's College of Engineering, Pandharpur

B.P Ronge, Professor,Department of mechanical Engineering, SVERI's College of Engineering, Pandharpur

\author{
$>$ Developing \\ $>$ Etching \\ $>$ Stripping and inspection
}

In three-dimensional PCM variable depth can be achieved by less and more exposing of samples. The less and more intensity of light will be got by passing light in coloured photo tool. The coloured photo tool is made up by printing different colours on a transparent sheet. the intensity of light passing through different colours is different. The light coming out from different is depending on the characteristic of different colours. The energy content of light is varying with colour by colour, which results in less and more harden of photoresist material. the 3D etching process is mainly depending on a development of photoresist material. Less developing results in less etching and more developing results in more etching.

The application of PCM has widely been used in the manufacturing of thin, flat and complex metal parts (i.e. lead frames, colour TV masks, sensors, heat plates, printed circuit boards) in electronics, precision engineering and decorative industries in the past forty years. Now a days PCM industries plays important role in production of varieties of precision parts, decorative components and to develop microfluidic channels, microfilters, copper printed circuit boards etc.

The photoresist used PCM has two types given below

\section{> Positive photoresist \\ $>$ Negative photoresist}

In negative photoresist part which is dark in photo-tool is removed and remaining part of photo-tool become hard and in positive photoresist inversely like negative photoresist the part which is dark is remain hard and other part will become softer and that non-harden part is removed.

Various studies have been reported on the depth analysis, parametric analysis, edge deviation analysis for photochemical machining. The photochemical machining has already been used by various researchers for fabrication of microchannel molds, heat sinks, grooving in hydrodynamic journal bearing, etc. [7-17]. No significant study has been observed on 3D PCM. Thus, there is a scope for 3D PCM for any material and its parametric analysis.

\section{METHODOLOGY}

A. Material selection: -

Thecopper is the material used for this study, because it is more elastic after gold and aluminium. Also, it has warm and higher electric conductivity. The size of specimen used is 30 $\mathrm{mm} \times 30 \mathrm{~mm} \times 0.740 \mathrm{~mm}(\mathrm{~W} \times \mathrm{L} \times \mathrm{T})$. Initially 3D PCM was 
carried out for flat surfaces of copper, then it did for curved objects of copper.

\section{B. Experimental procedure: -}

\section{Creating Phototool: -}

Photochemical machining process is carried out by using a photo tool. The photo tool is an AutoCAD drawing with detailed dimensions of the required shape which is then printed on a tress paper or transparent paper. The photo tool used in 3D PCM is colored photo tool i.e. made up by printing different colors on transparent sheet. The Fig.1 and Fig.2 shows the design of photo tool by using AutoCAD software and design is printed on transparent sheet.

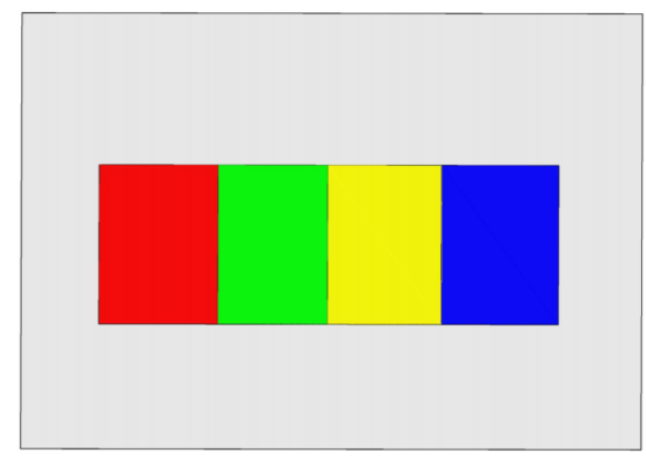

Fig.1.Colored photo tool

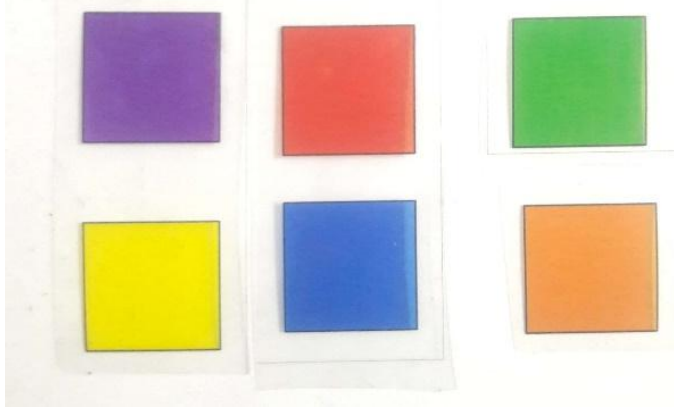

Fig. 2. Colored photo for etching

\section{Preparation of workpiece: -}

After preparing the photo tool the copper material is cut into required size. The first task is to clean the workpiece. The cleaning of the surface is done firstly by polishing the surface with a sand paper and then cleaning it by thinner (trichloroethylene or acetone). This step is done to make the surface of workpiece free from foreign particles, debris, dust, grease, oil and other contaminants. Because of polishing and cleaning with thinner it gets easier to have a good adhesion of photoresist with the metal surface.

\section{Coating of workpiece: -}

After cleaning the workpiece, a thin layer of photoresist is applied on the metal surface. The negative type photo resist was used for experimentation. The characteristic of negative photoresist is it get harden when UV light is incident on it. The properties of negative photoresist for different colors is different, it depends on the energy content of light coming out from colored photo tool. The photoresist and developer used in experimentation is shown in Fig. 3.

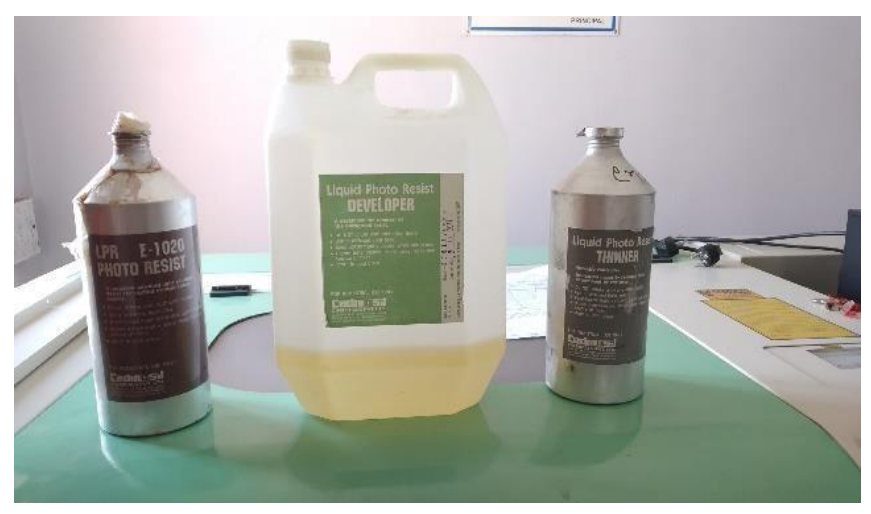

Fig.3.Photoresist and developing solution

\section{UV Exposure: -}

In three-dimensional photochemical marching, it is necessary to expose material (base metal) in all directions, the etching can be takes place in all directions. The 2D Exposure machine is designed in such a way that in can expose the specimen in all direction. It radiates the intensity 1800 microwatt per centimeter square at $25 \mathrm{~cm}$ distance. In traditional machining i.e. in 2D PCM process the samples are exposed in only one direction. The generated photo tool is put on the coated workpiece and exposed to UV source for 90seconds. The fig. 4 shows the UV source used in PCM process.

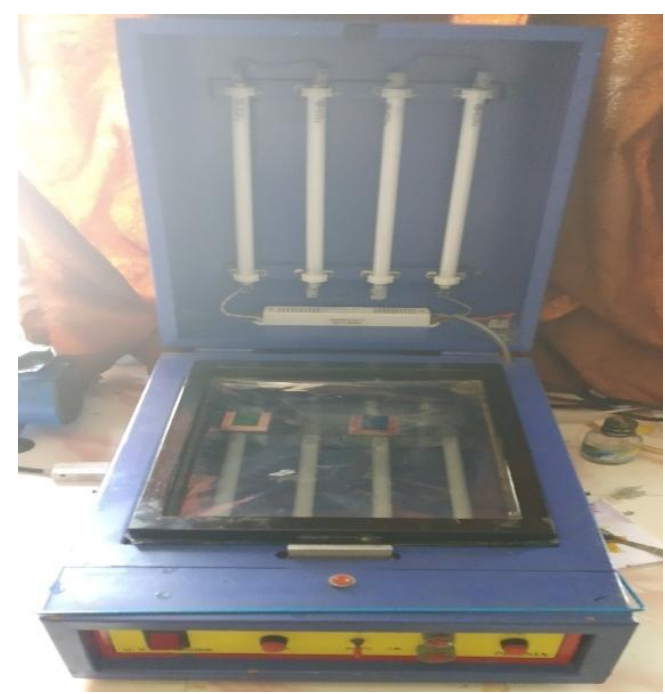

Fig.4. Exposure machine

\section{Development Phase: -}

The developing solution is the mixture of sodium carbonate and water. After UV exposure the specimen is held in the developer for 90 seconds, which results in the formation of impression on workpiece. After that specimen is washed with water. The developing of photoresist is different for different colors. The three-dimensional etching is mainly depending on the uneven developing of photoresist i.e. more developing results in more etching and vice versa. Which also means that if photoresist development relates with the etching process.

\section{Etching: -}

The final step of the machining is to put the developed metal workpiece into the etchant. The etchant is the solution of $\mathrm{FeCl}_{3}$ and water. In 3D etching of the component can be done 
by late etching process, i.e. the etching of metal is varying with colors. Some colors are etched more and some are etched less. In conventional etching process the photo tool is black and white, in which only etching of black color is happen and there is no effect on white color. In 3D etching number of colors are used to get variable depth. Thephotoresist thickness is varying with color.The fig.5 shows the beaker etching unit.

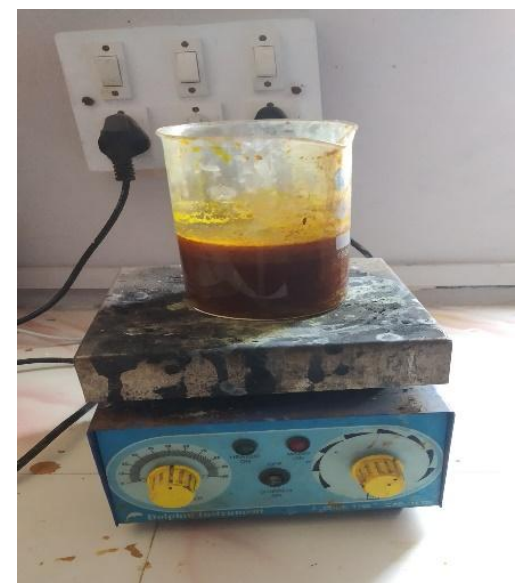

Fig.5 Etching Unit

\section{Experimental Analysis}

The numbers of experiment were performed to analyze etching behavior of copper material by using different colors. The input parameters are etching time, temperature etc. and response parameters are etching depth and surface roughness. The average values of response parameter are taken to analyze etching behavior.The other parameters like photoresist thickness, exposing time and developing time are kept constant throughout the experiments.

The experimental values are shown in below table 1 .

Table 1. Color and etching depth relation

\begin{tabular}{|c|c|c|c|c|c|c|}
\hline \multicolumn{2}{|c|}{ Input value } & \multicolumn{4}{|c|}{ Etching depth in microns } \\
\hline Temp & Time & V & B & Y & R & O \\
\hline 47 & 1 & 02 & 03 & 06 & 08 & 10 \\
\hline 47 & 2 & 05 & 07 & 10 & 15 & 19 \\
\hline 47 & 3 & 08 & 12 & 17 & 23 & 29 \\
\hline 49 & 1 & 04 & 07 & 09 & 11 & 14 \\
\hline 49 & 2 & 09 & 16 & 20 & 24 & 30 \\
\hline 49 & 3 & 15 & 21 & 29 & 37 & 47 \\
\hline 51 & 1 & 07 & 09 & 11 & 15 & 19 \\
\hline 51 & 2 & 17 & 22 & 25 & 33 & 41 \\
\hline 51 & 3 & 22 & 28 & 40 & 54 & 62 \\
\hline
\end{tabular}

\section{RESUlt AND DisCUSSION}

A. Comparison of light intensity at difference thicknesses of photo tool.

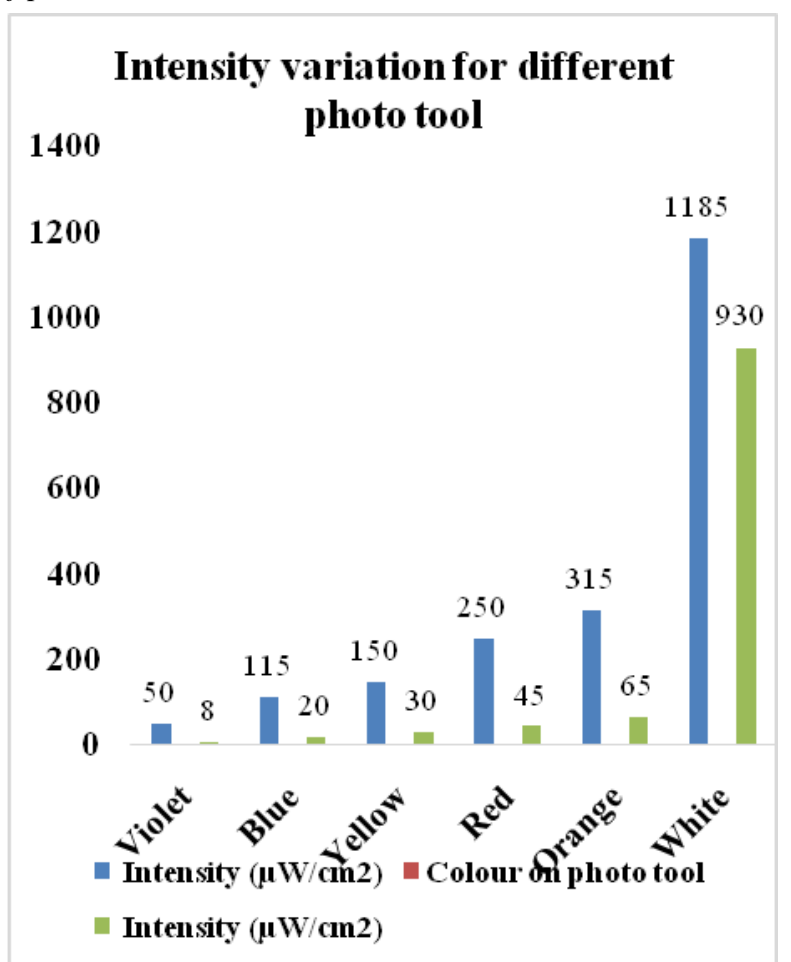

Fig.6. Photo tool thickness and intensity relation

The Fig.6 shows the comparison of intensity of light for 80 microns and 160 microns photo tool.

From above graph, it is seen that white color passes more intensity of light and violet passes less intensity. It is seen that, the photo tool thickness increases, the intensity of light passing decreases. The 80 microns photo tool passes more light compared to other 160 microns photo tool. The hardness value of photoresist is different for different size of photo tool. It is inversely proportional to the thickness of photo tool.

\section{B. Comparingetching behavior of coppermaterial at different time interval}

\section{i. Etching temperature 47 degree}

The below Fig. 7 shows the etching depth of copper material at different time i.e. ED1, ED2and ED3 minutes, respectively at temperature of 47 degree.

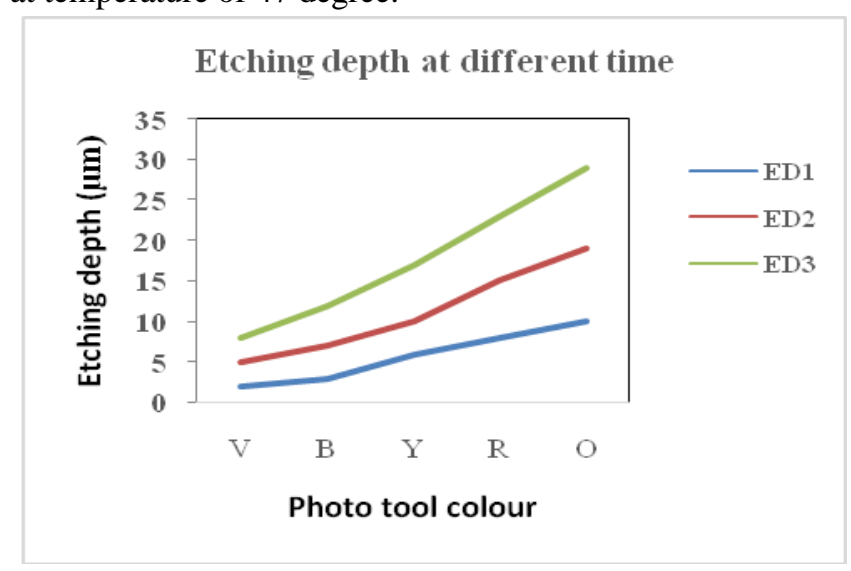

Fig.7. ED of color at different time at $47^{\circ} \mathrm{C}$. 


\section{ii. Etching temperature 49 degree}

The below Fig. 8 shows the etching depth of copper material at different time i.e. 1,2 and 3 minutes respectively at temperature of 49 degree.

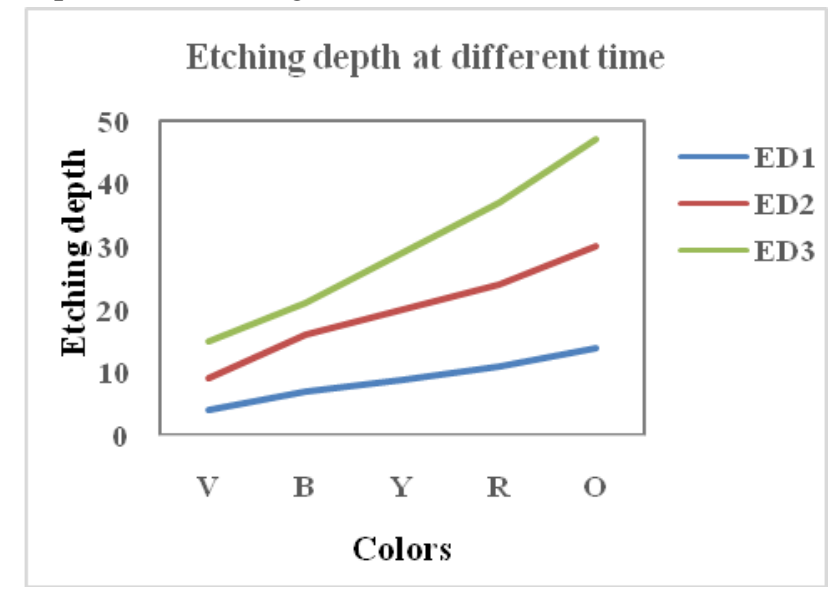

Fig.8. ED of color at different time at $49^{\circ} \mathrm{C}$.

\section{iii. Etching temperature 51 degree}

The below Fig.9 shows the etching depth of copper material at different time i.e. 1,2 and 3 minutes respectively at temperature of 51 degree.

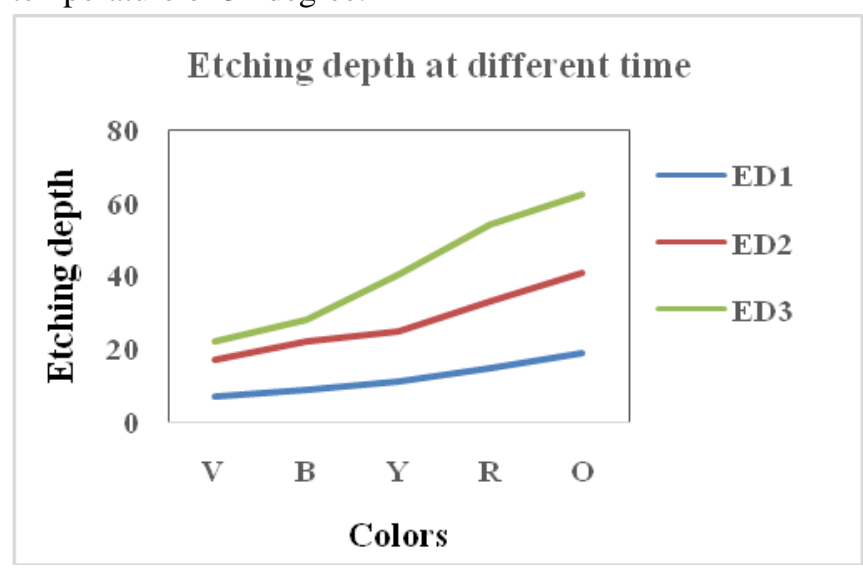

Fig.9. ED of color at different time at $51^{\circ} \mathrm{C}$.

\section{Finished components}

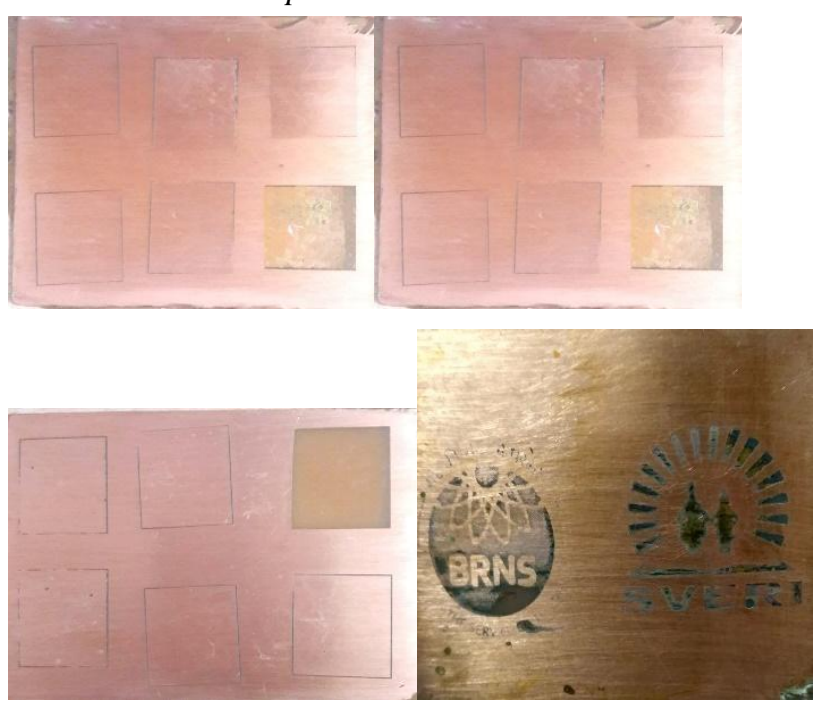

Fig.10. Finished components

The Fig.10 shows the finished components of PCM process.

\section{CONCLUSION}

The present study investigates the depth of etching for different colors on photo-tools. The etching time and depth of etching was investigated. As per this study, following conclusions were made.

1. In this study, process parameters were kept constant and the effect of response parameterswerestudied by using colored photo tool.

2. Depth of etching is directly depending on the energy of light coming out from different colors. Also, it depends on the photoresist thickness. The more is the thickness, the etching depth is less.Fig. 6 shows the intesity of light coming out from 80 microns photo tool is more and 160 microns photo tool its less.

3. The more etching depth obtained for orange color i.e. 62 microns.

4. The lowest depth obtained for violet color i.e 2 microns.

\section{REFERENCES}

[1]. Cakir, O, 2006, "Copper etching with cupric chloride and regeneration of waste etchant", journal of materials processing technology, 175, 63-68

[2]. Allen, David M., Almond, Heather J.A, 2004, "Characterization of aqueous ferric chloride etchants used in industrial photochemical machining", Journal of Materials Processing Technology, 149, 238-245.

[3]. Wangikar, S. S., Patowari, P. K., \&Misra, R. D. (2017). Effect of process parameters and optimization for photochemical machining of brass and german silver. Materials and Manufacturing Processes, 32(15), 1747-1755.

[4]. Wangikar, S. S., Patowari, P. K., \&Misra, R. D. (2016, December) Parametric Optimization for Photochemical Machining of Copper Using Grey Relational Method. In Techno-Societal 2016, International Conference on Advanced Technologies for Societal Applications (pp 933-943). Springer.

[5]. Wangikar, S.S., Patowari, P.K., \&Misra, R.D. (2018). Parametric Optimization for Photochemical Machining of Copper using Overal Evaluation Criteria. Materials Today Proceedings. 5(2), 4736-4742, Doi :10.1016/j. matpr.2017.12.046

[6]. Wangikar, S. S., Patowari, P. K., Misra, R. D., \&Misal, N. D. (2019) Photochemical Machining: A Less Explored Non-Conventional Machining Process. In Non-Conventional Machining in Modern Manufacturing Systems (pp. 188-201). IGI Global.

[7]. Raut, M. A., Kale, S. S., Pangavkar, P. V., Shinde, S. J., Wangikar, S S., Jadhav, S. V., \&Kashid, D. T. (2019) Fabrication of Micro Channe Heat Sink by using Photo Chemical Machining.International Journal of New Technology and Research. 5(4), 72-75.

[8]. Jadhav, S. M., Karatkar O. V., Bangale K. N., ChoudhariD. B., Utpat A. A., KambleB. K. (2019) Etching Depthvariation of Brass Materia for Different Operating Conditions, International Journal of New Technology and Research. 5(4), 93-96.

[9]. Khajepawar, S. S., Badave, G. V., Bhosale, S. S., Telang, D. S. MisalN. D. (2019) Study of depth of etching in Photo Chemical Machining by colouredPhototool, International Journal of New Technology and Research. 5(4), 68-71

[10]. Vhare, C. K., Chavan, V. R., Shinde, A. A., Solage, R. D., Jadhav S. S., (2019) Edge Deviation Analysis for Photochemical Machining of Copper. International Journal of New Technology and Research. 5(6), 45-47.

[11]. N. D. Misal, and M. Sadaiah, "Investigation on Surface Roughness of Inconel 718 in Photo chemical Machining", Advances in Materials Science and Engineering, 2017.

[12]. N. D. Misal, A. R. Saraf, and M. Sadaiah, "Experimental investigation of surface topography in photo chemical machining of Inconel 718", Materials and Manufacturing Processes, vol. 32, no. 15, pp.1756-1763, 2017.

[13]. Wangikar, S. S., Patowari, P. K., \&Misra, R. D. (2018). Numerical and experimental investigations on the performance of a serpentine 
microchannel with semicircular obstacles. Microsystem Technologies. 24(8), 3307-3320.

[14]. Das, S. S., Tilekar, S. D., Wangikar, S. S., \&Patowari, P. K. (2017). Numerical and experimental study of passive fluids mixing in micro-channels of different configurations. Microsystem Technologies, 23(12), 5977-5988.

[15]. Chavan, N. V., Bhagwat, R. M., Gaikwad, S. S., Shete, S. S., Kashid, D. T., \&Wangikar, S. S. (2019). Fabrication \& Characterization of Microfeatures on PMMA Using CO2 Laser Machining.International Journal for Trends in Engineering and Technology. 36(1), 39-32.

[16]. Kulkarni, H. D., Rasal, A. B., Bidkar, O. H., Mali, V. H., Atkale, S. A., Wangikar, S. S., \& Shinde, A. B. (2019). Fabrication of Micro-Textures on Conical Shape Hydrodynamic Journal Bearing. International Journal for Trends in Engineering and Technology. 36(1), 37-41.

[17]. Shinde, A., Pawar, P., Shaikh, P., Wangikar, S., Salunkhe, S., \&Dhamgaye, V. (2018). Experimental and numerical analysis of conical shape hydrodynamic journal bearing with partial texturing. Procedia Manufacturing, 20, 300-310. 